\title{
A commentary on "Urea, the most abundant component in urine, cross-reacts with a commercial 8-OH-dG ELISA kit and contributes to over-estimation of urinary 8-OH- dG". What is ELISA detecting?
}

Marcus S. Cooke

\author{
Radiation and Oxidative Stress Section, \\ Dept. Cancer Studies and Dept. Genetics, \\ Robert Kilpatrick Clinical Sciences Building, \\ University of Leicester. LE2 7LX, UK. \\ e-mail: msc5@le.ac.uk
}

Accepting the caveats concerning possible confounding influence from diet and cell death [1], the measurement of 8-oxo-7,8-dihydro-2'-deoxyguanosine (8-oxodG, or 8-OH-dG) in urine is thought to provide a non-invasive assessment of whole body oxidative stress. This represents a number of advantages over other possible biomarkers of oxidative stress. The non-invasive nature of the assay make it less of an ethical issue than, for example, bloodbased assessments of oxidative stress, in particular when sampling from vulnerable groups is required. Many of the issues of adventitious damage, associated with the study of cellular 8oxodG [2], are circumvented by analysis of urine. Urine is easily collected and transported. No special storage conditions are required, for example no preservatives are necessary, with 8-oxodG reported to be stable in urine, at $-20^{\circ} \mathrm{C}$, for over 10 years [3], making previously collected samples eminently suitable for analysis. Such urinary biomarkers can therefore be used in both prospective and nested, case-control molecular epidemiology studies [4].

For the most part, methods that have been applied to the analysis of oxidatively damaged DNA lesions have been based upon chromatography (principally, HPLC-MS/MS; 
liquid chromatography pre-purification prior to GC-MS, HPLC-GC/MS, HPLC-EC, GC-MS [5]). However, a significant number of reports in the literature use competitive enzymelinked immunosorbant assay (ELISA), and in particular the commercially available kit from the Japanese Institute for the Control of Aging (JaICA), although use of 'custom made' ELISAs has also been reported [6-8]. The benefits of ELISA are (i) ease of use; (ii) no specialist (or indeed expensive) equipment is required; (iii) potential application to numerous extracellular matrices (serum [9], plasma [10], saliva [11, 12], urine [13], CSF [14, 15], cell culture medium [16-18] and sputum [19], in contrast to the, to date, rather limited repertoire of matrices analysed by chromatographic techniques, with the exception of that reported by Bogdanov et al. [20] ; (iv) other than centrifugation of cloudy specimens, no pre-treatment of urine is required (v) high throughput.

However, there exists major criticisms of ELISA concerning (i) lack of perfect correlation with established chromatographic techniques, and (ii) apparent over-estimation of background levels of urinary 8-oxodG in healthy individuals. Whilst correlations have been demonstrated between the ELISA and chromatographic techniques e.g. $r=0.46$ [21], $r_{s}=$ 0.56 [22], (both) $\mathrm{p}<0.001$ vs. HPLC-ECD; and $\mathrm{r}=0.73, \mathrm{p}=0.002$ vs. HPLC-GC/MS [23] these have been far from 1:1 and statistical significance is not always achieved [24]. Differences in mean urinary 8-oxodG levels can vary anywhere from four- to ten-fold between ELISA and chromatographic techniques. Overall, this does suggest that both techniques share a common analyte, with the ELISA perhaps recognising additional compounds, and as a consequence a number of groups have been actively trying to address this the issue of discrepancy. For example, improvements by the manufacturer of the JaICA kit (narrowing calibration curve range; recommendation for strict temperature control), have reduced the margin in background levels between the two approaches. More recently, further 
improvements have been noted, following overnight incubation of the primary antibody at 4 ${ }^{\circ} \mathrm{C}[25]$.

Data concerning the antigens recognised by the primary antibody of the JaICA kit (denoted N45.1) suggest the antibody to be highly specific for 8-oxodG [26]. This, in part, derives from recognition of the hydroxylated C8 position of Gua, it would appear to discriminate the $\mathrm{C} 6$ carbonyl group of 8-oxoGua (and $\mathrm{C} 2 \mathrm{NH}_{2}$ ), from the $\mathrm{C} 6$ amino group of 8-oxoAde. Furthermore, the closest competitors, other than 8-oxodG, for the antibody is 8oxo-7,8-dihydroguanosine (8-oxoGuo) and 8-oxodGMP [25], the former of which needs to be present in concentrations two orders of magnitude higher than 8-oxodG, in order to compete to the same extent [26], a situation that does not appear to occur in vivo [27]. It is unknown whether 8-oxodGMP is present in urine. Toyokuni et al. [26] also reported that other endogenous constituents, present at high concentrations, in urine, such as uric acid, urea and creatinine, show no cross-reactivity with the antibody.

In this issue of Free Radical Biology and Medicine, Song et al. [28] demonstrate that urea is, in fact, one of the major contributors to the over-estimation of urinary 8-oxodG by ELISA. The authors' approach to better understand the reactivity of N45.1 is to fractionate a human urine sample, and to test aliquots of these fractions for reactivity in the ELISA. The first eluting ELISA-positive fractions was, using retention time as a guide, surmised to contain urea and allantoin, the second fraction contained 8-oxodG. Both urea and allantoin were then screened in the ELISA, with urea demonstrating competition with 8-oxodG for antibody binding. This raises the question 'why this was not noted during antibody characterisation?'. In the work of Song et al. [28], a urea concentration of $10-80 \mathrm{mg} / \mathrm{mL}$ was used, levels similar to that seen in human urine. In contrast, the concentrations used during the characterisation of N45.1 were four orders of magnitude lower than that present in human urine, explaining the apparent lack of reactivity [26]. This raises the possibility that urease 
treatment of urine, prior to ELISA may bring the results into closer agreement with a chromatographic approach. Indeed, this does appear to be the case. The authors also exploited a recent development in which performing the JaICA ELISA kit's primary antibody step at $4{ }^{\circ} \mathrm{C}$, rather than $37{ }^{\circ} \mathrm{C}$, improved the agreement between ELISA and LC-MS/MS [25]. This further decreased the recognition of urea by N45.1, and demonstrated the most significant correlation with HPLC-EC, to date $(r=0.98 ; p<0.0001)$. The authors conclude that other, as yet unidentified, cross-reacting substances may be present in urine, which account for the remaining disagreement with chromatographic techniques. They also note that, in their study, only a 7-fold greater concentration of 8 -oxoGuo is required to compete for 8-oxodG, unlike the previous reports of one or two orders of magnitude [25, 26].

Identifying the basis of the discrepancy between ELISA and chromatographic assays has proven to be problematic, but some progress has been made [25]. The report of Song et al. [28] has further added to our understanding of the discrepancy between ELISA and chromatographic method, and hence indicated possible ways to further improve the ELISA. Nevertheless, there still remains a discrepancy, even with urease pre-treatment, or low temperature incubation of the primary antibody. Further work is clearly required, not least to further validate the use of these methodological improvements, before ELISA can be recommended, without comparison with established chromatographic methods, for the specific measurement of urinary 8-oxodG.

\section{Acknowledgements}

MSC is a partner of ECNIS (Environmental Cancer Risk, Nutrition and Individual Susceptibility), a network of excellence operating within the European Union $6^{\text {th }}$ Framework Program, Priority 5:"Food Quality and Safety" (Contract No 513943). Research in MSC's 
laboratory is supported by the ECNIS, World Cancer Research Fund (WCRF UK), bioKnex and Telethon Institute for Child Health.

\section{References}

[1] Cooke, M. S., Lunec, J. and Evans, M. D. Progress in the analysis of urinary oxidative DNA damage. Free Radic Biol Med 2002; 33:1601-1614.

[2] Gedik, C. M. and Collins, A. Establishing the background level of base oxidation in human lymphocyte DNA: results of an interlaboratory validation study. Faseb J 2005; 19:8284.

[3] Loft, S., Svoboda, P., Kasai, H., Tjonneland, A., Vogel, U., Moller, P., Overvad, K. and Raaschou-Nielsen, O. Prospective study of 8-oxo-7,8-dihydro-2'-deoxyguanosine excretion and the risk of lung cancer. Carcinogenesis 2006; 27:1245-1250.

[4] Loft, S. and Moller, P. DNA base oxidation and repair. In: State of validation of biomarkers of carcinogen exposure and early effects and their applicability to molecular epidemiology. (Eds P. B. Farmer, S. A. Kyrtopoulos and J. M. Emeny). Nofer Institute of Occupational Medicine, Lodz: pp. 32-39.

[5] Cooke, M. S., Olinski, R. and Loft, S. Measurement and meaning of oxidatively modified DNA lesions in urine. Cancer Epidemiol Biomarkers Prev 2008; 17:3-14.

[6] Chiou, C. C., Chang, P-Y., Chan, E-C., Wu, T-L., Tsao, K-C. and Wu, J. T. Urinary 8-hydroxydeoxyguanosine and its analogs as DNA markers of oxidative stress: development of an ELISA and measurement in both bladder and prostate cancers. Clinica Chimica Acta $2003 ; 334: 87-94$.

[7] Yin, B., Whyatt, R. M., Perera, F. P., Randall, M. C., Cooper, T. B. and Santella, R. M. Determination of 8-hydroxydeoxyguanosine by an immunoaffinity chromatographymonoclonal antibody-based ELISA. Free Radic Biol Med 1995; 18:1023-1032. 
[8] Rossner, P., Jr., Svecova, V., Milcova, A., Lnenickova, Z., Solansky, I., Santella, R. M. and Sram, R. J. Oxidative and nitrosative stress markers in bus drivers. Mutat Res 2007; 617:23-32.

[9] Breton, J., Sichel, F., Bianchini, F. and Prevost, V. Measurement of 8-hydroxy-2'deoxyguanosine by a commercially available ELISA test: comparison with HPLC/electrochemical detection in calf thymus DNA and determination in human serum. Anal Lett 2003; 36:123-134.

[10] Tope, A. M. and Panemangalore, M. Assessment of oxidative stress due to exposure to pesticides in plasma and urine of traditional limited-resource farm workers: formation of the DNA-adduct 8-hydroxy-2-deoxy-guanosine (8-OHdG). J Environ Sci Health B 2007; 42:151-155.

[11] Sawamoto, Y., Sugano, N., Tanaka, H. and Ito, K. Detection of periodontopathic bacteria and an oxidative stress marker in saliva from periodontitis patients. Oral Microbiol Immunol 2005; 20:216-220.

[12] Sugano, N., Yokoyama, K., Oshikawa, M., Kumagai, K., Takane, M., Tanaka, H. and Ito, K. Detection of Streptococcus anginosus and 8-hydroxydeoxyguanosine in saliva. J Oral Sci 2003; 45:181-184.

[13] Yoshida, R., Ogawa, Y. and Kasai, H. Urinary 8-oxo-7,8-dihydro-2'-deoxyguanosine values measured by an ELISA correlated well with measurements by high-performance liquid chromatography with electrochemical detection. Cancer Epidemiol Biomarkers Prev 2002; 11:1076-1081.

[14] Ihara, Y., Takata, H., Tanabe, Y., Nobukuni, K. and Hayabara, T. Influence of repetitive transcranial magnetic stimulation on disease severity and oxidative stress markers in the cerebrospinal fluid of patients with spinocerebellar degeneration. Neurol Res 2005; 27:310-313. 
[15] Kikuchi, A., Takeda, A., Onodera, H., Kimpara, T., Hisanaga, K., Sato, N., Nunomura, A., Castellani, R. J., Perry, G., Smith, M. A. and Itoyama, Y. Systemic increase of oxidative nucleic acid damage in Parkinson's disease and multiple system atrophy. Neurobiol Dis 2002; 9:244-248.

[16] Cooke, M. S., Patel, K., Ahmad, J., Holloway, K., Evans, M. D. and Lunec, J. Monoclonal antibody to single-stranded DNA: a potential tool for DNA repair studies. Biochem Biophys Res Commun 2001; 284:232-238.

[17] Haghdoost, S., Czene, S., Naslund, I., Skog, S. and Harms-Ringdahl, M. Extracellular 8-oxo-dG as a sensitive parameter for oxidative stress in vivo and in vitro. Free Radic Res 2005; 39:153-162.

[18] Kantha, S. S., Wada, S., Tanaka, H., Takeuchi, M., Watabe, S. and Ochi, H. Carnosine sustains the retention of cell morphology in continuous fibroblast culture subjected to nutritional insult. Biochem Biophys Res Commun 1996; 223:278-282.

[19] Kulkarni, N., Cooke, M. S. and Grigg, J. Neutrophils in induced sputum from healthy children: role of interleukin-8 and oxidative stress. Respir Med 2007; 101:2108-2112.

[20] Bogdanov, M. B., Beal, M. F., McCabe, D. R., Griffin, R. M. and Matson, W. R. A carbon column-based liquid chromatography electrochemical approach to routine 8-hydroxy2'-deoxyguanosine measurements in urine and other biologic matrices: a one-year evaluation of methods. Free Radic Biol Med 1999; 27:647-666.

[21] Shimoi, K., Kasai, H., Yokota, N., Toyokuni, S. and Kinae, N. Comparison between high-performance liquid chromatography and enzyme-linked immunosorbent assay for the determination of 8-hydroxy-2'-deoxyguanosine in human urine. Cancer Epidemiol Biomarkers Prev 2002; 11:767-770.

[22] Cooke, M. S., Barregard, L., Mistry, V., Potdar, N., Rozalski, R., Gackowski, D., Siomek, A., Foksinski, M., Svoboda, P., Kasai, H., Konje, J. C., Sallsten, G., Evans, M. D. 
and Olinski, R. Interlaboratory comparison of methodologies for the measurement of urinary 8-oxo-7,8-dihydro-2'-deoxyguanosine. Biomarkers 2009; 14:103-110.

[23] Cooke, M. S., Rozalski, R., Dove, R., Gackowski, D., Siomek, A., Evans, M. D. and Olinski, R. Evidence for attenuated cellular 8-oxo-7,8-dihydro-2'-deoxyguanosine removal in cancer patients. Biol Chem 2006; 387:393-400.

[24] Prieme, H., Loft, S., Cutler, R. G. and Poulsen, H. E. Measurement of oxidative DNA injury in humans: evaluation of a commercially available ELISA assay. In: Natural Antioxidants and Food Quality in Atherosclerosis and Cancer Prevention (Eds J. T. Kumpulainen and J. T. Salonen). The Royal Society of Chemistry, London, 1996: pp. 78-82. [25] Evans, M. D., Singh, R., Mistry, V., Sandhu, K., Farmer, P. B. and Cooke, M. S. Analysis of urinary 8-oxo-7,8-dihydro-purine-2'-deoxyribonucleosides by LC-MS/MS and improved ELISA. Free Radic Res 2008; 42:831-840.

[26] Toyokuni, S., Tanaka, T., Hattori, Y., Nishiyama, Y., Yoshida, A., Uchida, K., Hiai, H., Ochi, H. and Osawa, T. Quantitative immunohistochemical determination of 8-hydroxy2'- deoxyguanosine by a monoclonal antibody N45.1: its application to ferric nitrilotriacetateinduced renal carcinogenesis model. Lab Invest 1997; 76:365-374.

[27] Weimann, A., Belling, D. and Poulsen, H. E. Quantification of 8-oxo-guanine and guanine as the nucleobase, nucleoside and deoxynucleoside forms in human urine by highperformance liquid chromatography-electrospray tandem mass spectrometry. Nucleic Acids Res 2002; 30:E7.

[28] Song, M.-F., Li, Y.-S., Ootsuyama, Y., Kasai, H., Kawai, K., Ohta, M., Eguchi, Y., Yamato, H., Matsumoto, Y., Yoshida, Y. and Ogawa, Y. Urea, the most abundant component in urine, cross-reacts with a commercial 8-OH-dG ELISA kit and contributes to overestimation of urinary 8-OH-dG. Free Rad. Biol. Med 2009. 
